\section{Breaking new ground}

Leeds Dental Institute is to launch the first ever practical training course, the Yorkshire Orthodontic Therapy course, for a new kind of health care professional: orthodontic therapists. The new orthodontic therapists will be able to work directly in the mouths of patients, taking a full and active role in orthodontic care. It is hoped the move will help combat the shortage of specialists in the field and make it easier for the huge number of children in the region who need orthodontic care to gain access to treatment.

Only ten dental nurses from across the UK were selected to join the 45-week course which will lead to a Diploma in Orthodontic Therapy. The course is the first 'hands on' dental course where the bulk of the training takes place outside a hospital setting.

It will start with a month of core training at Leeds Dental Institute and be completed either in an orthodontic practice or hospital department where the trainee therapists will work under the supervision of a specialist trainer. Once they have completed the course, the therapists, working under the supervision of an orthodontist, will be able to do much of the work traditionally done by orthodontists such as taking impressions, fitting orthodontic bands and placing and removing brackets and wires. Other centres in the UK are also interested in getting the ball rolling and similar training courses are already planned.

\section{Cash towards career development}

Kerry Zoina, Practice Manager of Confident Dental, has been awarded the 2007 BDPMA and Henry Schein Career Develtowards a nationally recognised professional qualification.

Having already completed her Diploma in Practice Management, Kerry is keen to pursue the development of her financial and team management skills. On receivopment Grant. She will receive $£ 2,500$ ing her award Kerry said, 'I am so thrilled to receive the grant and to have this opportunity to continue my professional development. We have so much more to do to realise our practice vision and now I can obtain the necessary skills to ensure I can lead the team and the practice to success.'

The 2008 BDPMA and Henry Schein Career Development Grant will be launched in the last quarter of 2007.

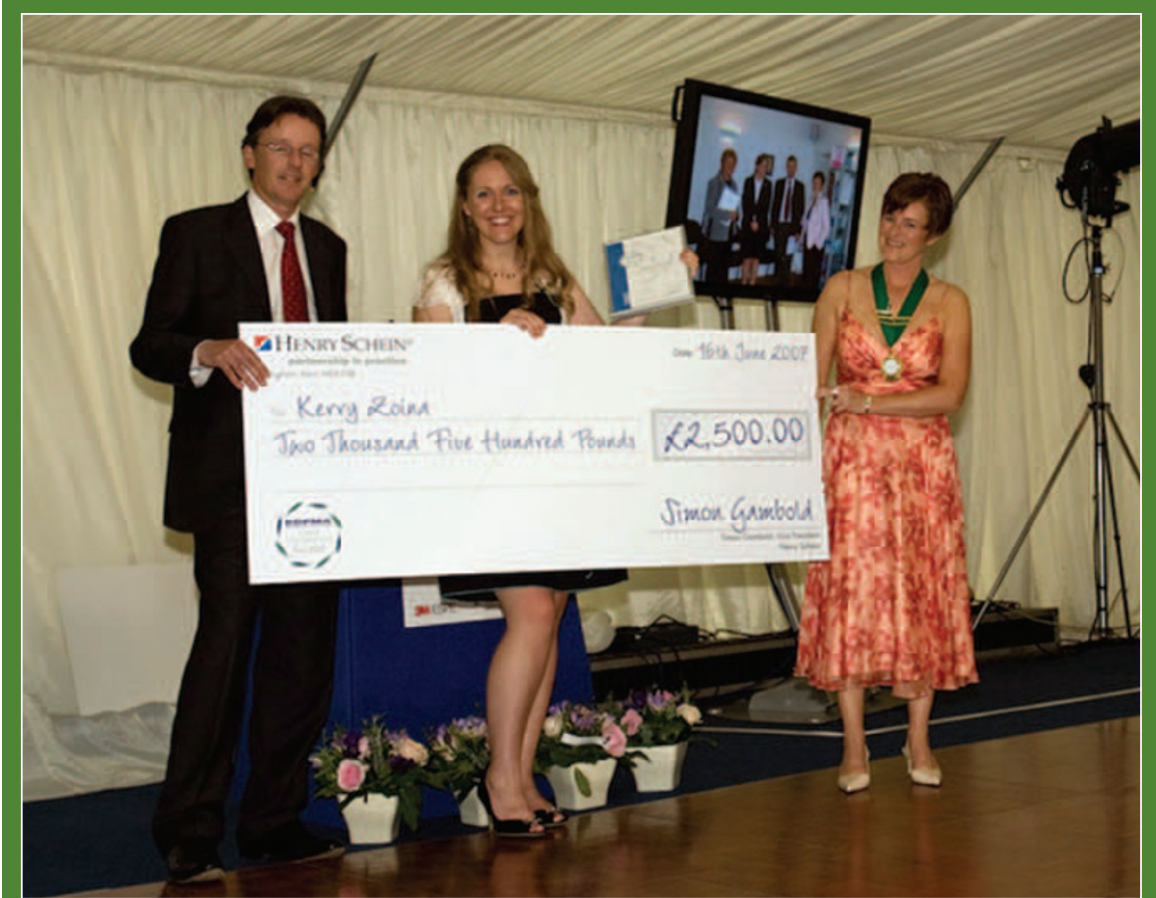

From left to right, Simon Gambold, VP Dental Sales \& Marketing, winner Kerry Zoina, Practice Manager of Confident Dental, and BDPMA Chairman, Bridget Crump

\title{
Compulsory CPD for DCPs
}

Following public consultation the GDC has agreed that all dental care professionals (DCPs) will be required to complete and record 150 hours of continuing professional development (CPD) every five years, a third of which should be verifiable (50 hours).

The Council expects to introduce the requirement from July 2008 when registration will become compulsory for dental nurses and technicians.

Dental care professionals will be required to complete CPD in the same core subjects as dentists which are medical emergencies (ten hours per cycle), disinfection and decontamination and radiography and radiation protection (both five hours per cycle).

Dental technicians should substitute radiography and radiation protection for materials and equipment (five hours per cycle) as radiography is not within the dental technician curriculum.

In line with the CPD scheme for dentists, the GDC is recommending that DCPs involved in the care of patients should undertake CPD in legal and ethical issues and complaints handling.

Duncan Rudkin, Chief Executive and Registrar, said, 'The CPD hours requirement is lower for dental care professionals than for dentists as $\mathrm{CPD}$ provision is still developing for these groups. We would like to see greater availability of training courses for dental care professionals and hope the introduction of compulsory CPD will drive this provision. Further information about CPD for DCPs is available on the GDC website at www.gdc-uk.org. 